\title{
The research on high-strength concrete creep
}

\author{
Chenkongliang ${ }^{1, \mathrm{a}^{*}}$, Wangronghui $^{2, \mathrm{~b}}$, Liaojianhong $^{3, \mathrm{c}}$ \\ ${ }^{1}$ School of Civil Engineering and architecture, WuYi University, Jiangmen, China \\ ${ }^{3}$ School of Civil Engineering and Transportation, South China University of Technology,Guangzhou, \\ China \\ ${ }^{3}$ Transportation Planning Survey and Design Institute of Hunan Province, China \\ ackongliang@163.com, brhwang@scut.edu.cn, cjianhongliao@126.com
}

Keywords: concrete, creep, strength

Abstract: By a series of creep test on and natural environment, the development trend and law of C60 high-strength concrete creep on natural environment are analyzed and the creep law of reinforced concrete is discussed in this article.

\section{The study on concrete creep}

Concrete creep is important physical and mechanical properties with respect to time, which is affected by the composition of material and external conditions and other factors, and the creep mechanism is so complex that there is not a completely accurate theory which could explain or predict concrete creep so far. Currently most of creep prediction models are based on experimental data and statistics obtained by fitting, and the research materials are mostly subjected to normal strength concrete, so the prediction models have some limitations because of few research on high-strength concrete currently. In addition, with the applications of the high-strength materials, new construction methods as well as geographical differences ${ }^{[1-8]}$. Therefore, further research on high-strength concrete creep show the importance and necessity.

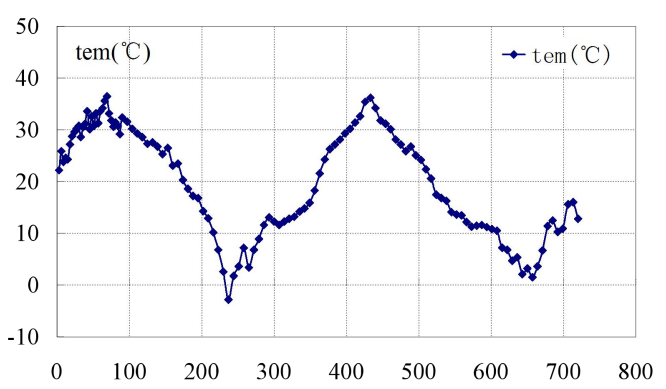

Fig. 1 The temperature of test environment

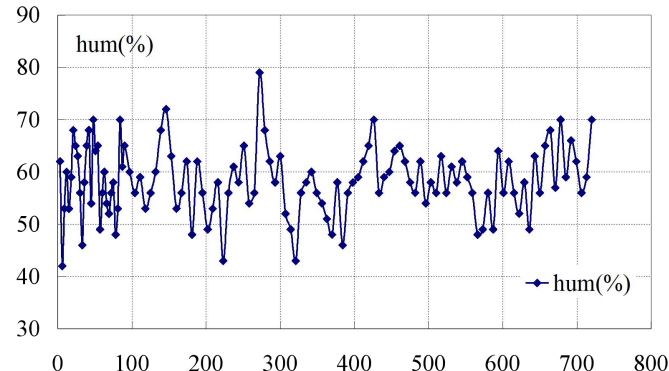

Fig.2 The humidity of test environment

\section{The creep test under natural environment}

\section{Creep test}

The researches on loading age, reinforcement ratio and other factors on high-strength concrete creep characteristics are through five groups of axial compression specimens under natural environment(shown in Figs.1-2). Each test component is made of a combination of three different age segments with $1 \mathrm{~m}$ segment length and $250 \mathrm{~mm} \times 250 \mathrm{~mm}$ section size. Three trials are designed, and reinforcement ratio are respective $0.3 \%, 0.72 \%$ and $1.45 \%$.The specimens loaded multi-age groups which designed a series loading age of $15 \mathrm{~d}, 30 \mathrm{~d}, 60 \mathrm{~d}$ etc, considering among different age segments. Creep specimens loaded with pre-stressed anchorage system with $15 \phi^{s} 9$ high strength 
steel of smaller loss, which are controlled 12Mpa.
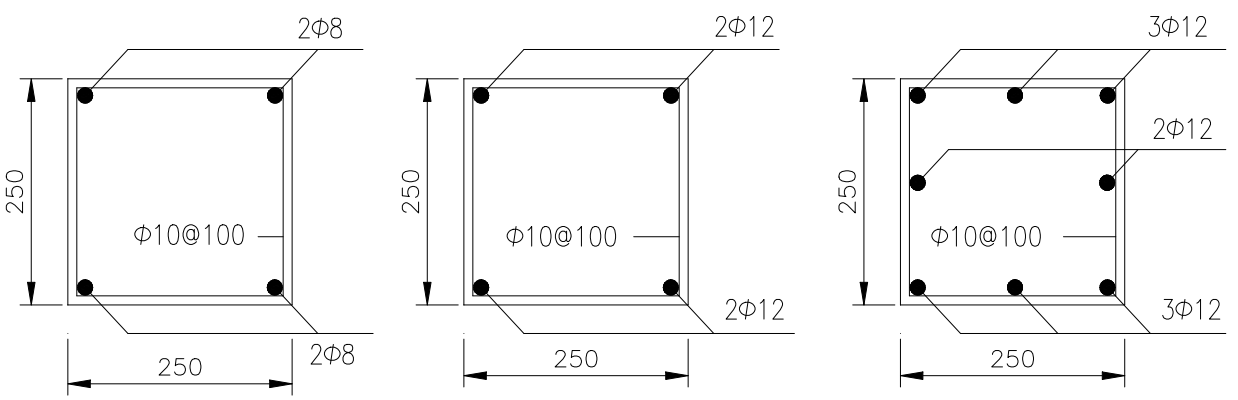

Fig.3 The creep specimen of reinforcement
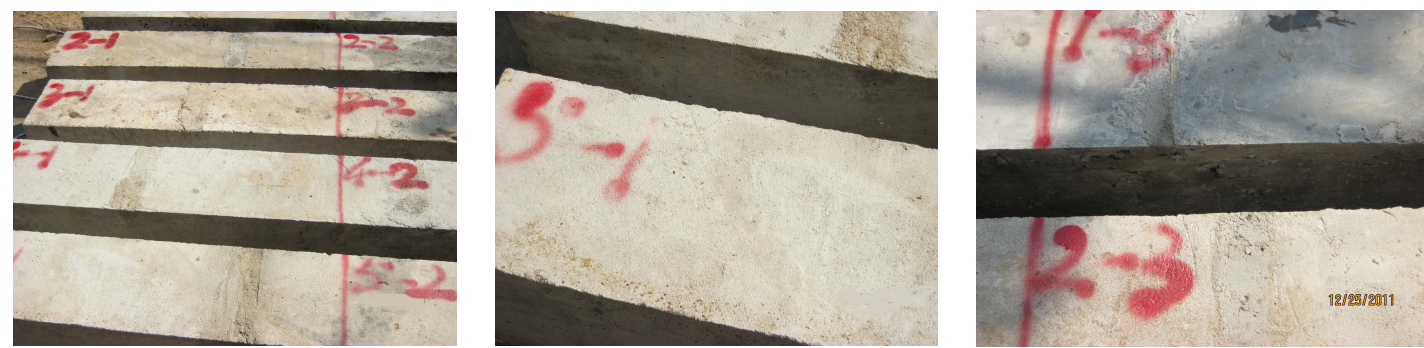

Fig.4 Creep specimen groups

Table 2 Creep groups

\begin{tabular}{ccccc}
\hline Specimen Group & Loading age & Reinforcement ratio & Loading stress & Picture \\
\hline 1 & $7 \mathrm{~d} 14 \mathrm{~d} 28 \mathrm{~d}$ & $0.30 \%$ & $12 \mathrm{MPa}$ & Fig.5 \\
2 & $7 \mathrm{~d} \mathrm{14d} \mathrm{28d}$ & $0.72 \%$ & $12 \mathrm{MPa}$ & Fig.6 \\
3 & $7 \mathrm{~d} 14 \mathrm{~d} 28 \mathrm{~d}$ & $1.45 \%$ & $12 \mathrm{MPa}$ & Fig.7 \\
4 & $15 \mathrm{~d} 30 \mathrm{~d} 60 \mathrm{~d}$ & $0.72 \%$ & $12 \mathrm{MPa}$ & Fig. 8 \\
\hline
\end{tabular}

\section{Test results of creep}

As shown in Fig.5, the creep coefficient curve is gradually flatten with the increase of time, of which the creep strain of $7 \mathrm{~d}$ specimen is maximum, and the creep strain of $14 \mathrm{~d}$ specimen is slightly larger than those of creep and $28 \mathrm{~d}$ specimen, and the creep strain in the previous 200 days is about $90 \%$ of the total creep.

As shown in Fig.6, the creep coefficient curve is gradually flatten with the increase of time, of which the creep strain of $7 \mathrm{~d}$ specimen is the maximum, and those of $28 \mathrm{~d}$ specimen is the minimum, and the creep strain in the previous 200 days is about $90 \%$ of the total creep. The results of comparative tests between group 1 and group 2 , the creep data is relatively close with the increase of reinforcement ratio, which indicating that the reinforcement ratio increased from $0.3 \%$ to $0.72 \%$ impact on the results of creep is not obvious.

As Shown in Fig.7, the creep coefficient curve is gradually flatten with the increase of time, of which the creep of $7 \mathrm{~d}$ specimen is the maximum, and those of $28 \mathrm{~d}$ specimen is the minimum; the creep strain in the previous 200 days is about $90 \%$ of the total creep. The results of comparative tests between group 1 and group 2 , the creep data is relatively close with the increase of reinforcement ratio, which indicating that the reinforcement ratio increased from $0.72 \%$ to $1.45 \%$ impact on the results of creep is relatively obvious.

As shown in Fig.8, the creep coefficient of 15d loading age specimen is the maximum, and those of $60 \mathrm{~d}$ loading age specimen creep coefficient is the minimum, and the creep coefficient curve is gradually flatten with the increases of time, and creep value in the first 200 days of the specimen is also nearing completion of $95 \%$ of the total creep values. Comparing test results between 4 and 5 groups, the creep result of $15 \mathrm{~d}, 30 \mathrm{~d}, 60 \mathrm{~d}$ is less than those of corresponding $10 \mathrm{~d}, 20 \mathrm{~d}, 40 \mathrm{~d}$ specimen, but no significant changes. 

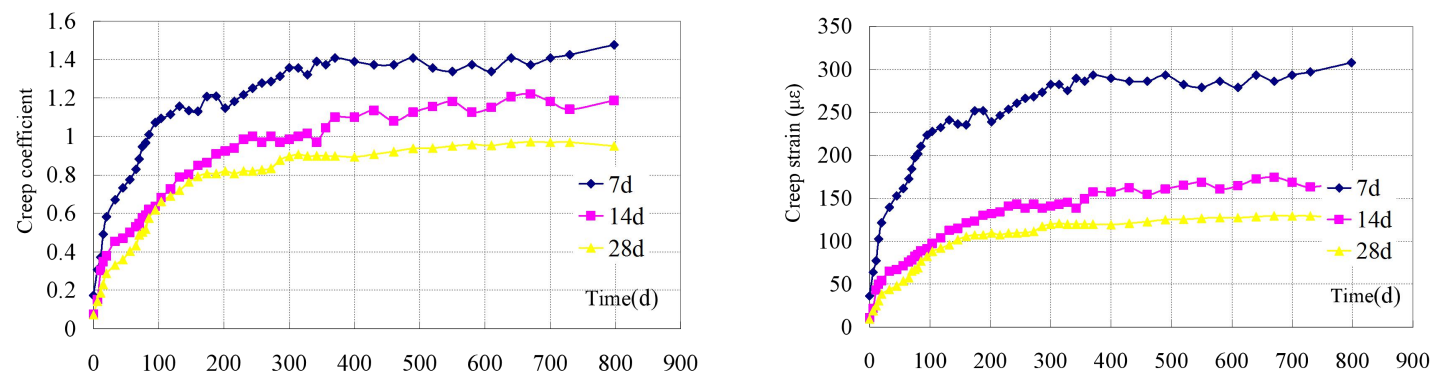

Fig.5 experimental Group $1(\rho=0.3 \%)$
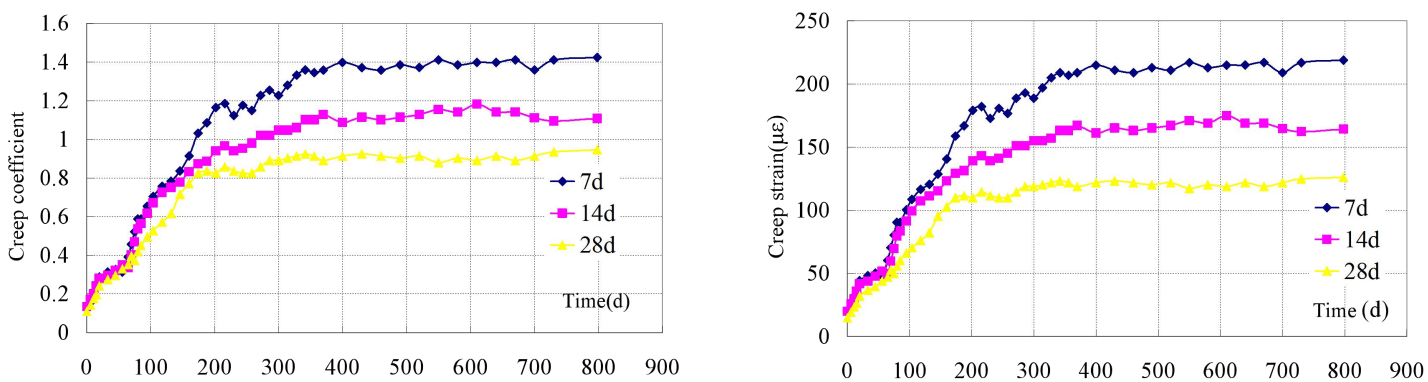

Fig.6 experimental Group $2(\rho=0.72 \%)$
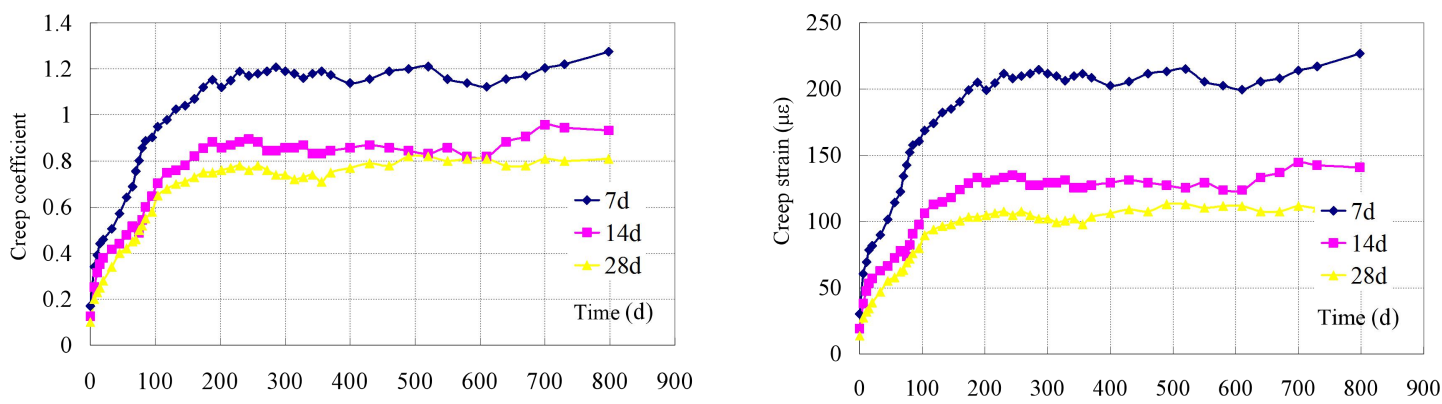

Fig.7 experimental Grou p $3(\rho=1.45 \%)$
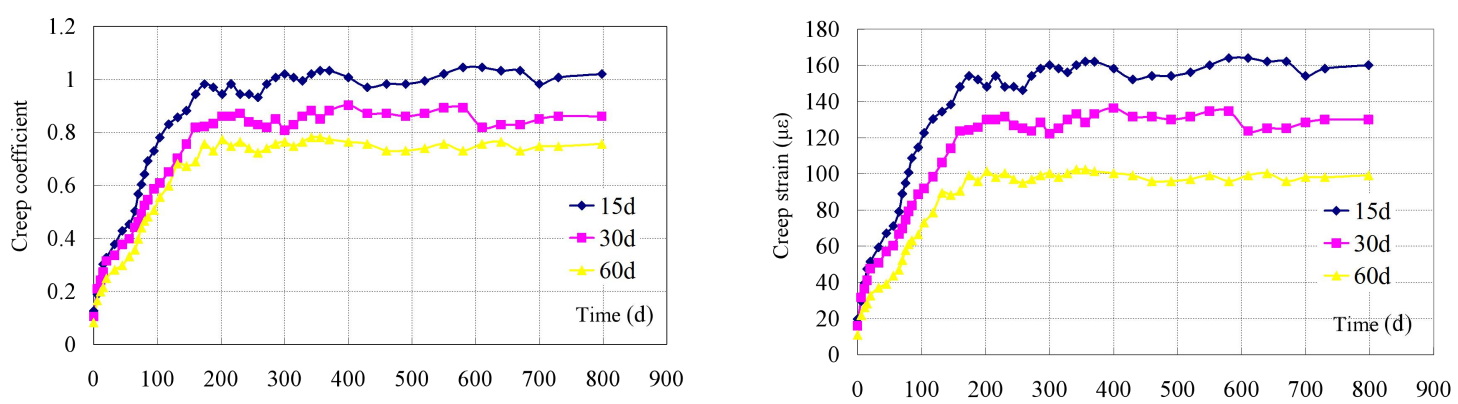

Fig.8 experimental Group 5 ( ( $\rho=0.72 \%)$

\section{Conclusion}

High-strength concrete creep tests under natural environment are concluded as follows:

The concrete creep coefficient decreases with increasing loading age. External factors such as environmental factors will be influenced the test results of concrete creep, and test results show that the short-term creep defer concrete loading age, which can effectively reduce early concrete creep.

The creep law of reinforced concrete is discussed in this paper, and creep values decreases 
with increasing reinforcement ratio, but the magnitude of decrease is not obvious.

\section{Acknowledgements}

The project surported (No. 200820) from Department of communication of Hunan Province, and surported (No.20140080089566) from Department of communication of Jiangmen.

\section{Reference}

[1] Bazant Z. P. and BAWEJA S. . Justification and refinements of model B3 for concrete creep and shrinkage statistic and sensitity. Materials and Structures, Vol.28(180). (1995) P. 415-430,

[2] Z. P. Bazant and S. Baweja. Creep and Shrinkage Prediction Model for Analysis and Design of Conerete Structures-Model B3 RILEM Reeonunendation, Materials and Structures, Vol.28, (1995) P.357-365.

[3] N. J, Gardner, J. W. Zhao. Creep and Shrinkage Revisited. ACI Materials Journal, Vol.90(.3), (1993) P. 236-246.

[4] N. J. Gardner and M. J. Lockman. Design, provisions for Drying shrinkage and Creep of Normal-StrengthConcrete.ACI Materials Journal, Vol.98, (2001). P. 159-167.

[5] J. Y. Li, Y. Yao. A study on creep and drying shrinkage of high performance concrete. Cement and Concrete Research, Vol.31. (2001) P.1203-1206.

[6] Bertil Persson. Correlating laboratory and field tests of creep in high-performance concrete , Cement and Concrete Research, Vol.31(3): 389-395, (2001)

[7] X.iang Xiaobin. Experimental study of concrete creep on span continuous rigid frame bridge, Wuhan: Wuhan University of Technology, (2007)

[8] Zengyan. Theoretical and experimental study of high-grade concrete creep. Wuhan University of Technology, (2005) 